\title{
Pressure ulcers in patients with diabetes: a bibliometrics analysis
}

\author{
Junhua Dong ${ }^{1}$, Lingxia $\mathrm{Li}^{2}$, Min $\mathrm{Lu}^{3}$, Xuejun Cheng ${ }^{4}$, Yucui Zhai ${ }^{5}$ \\ ${ }^{1}$ General Surgery, The Seventh Medical Center of Chinese People's Liberation Army General Hospital, Beijing, China; ${ }^{2}$ Department of Hematology, \\ The Seventh Medical Center of Chinese People's Liberation Army General Hospital, Beijing, China; ${ }^{3}$ Department of Cardiovascular Surgery, The \\ Seventh Medical Center of Chinese People's Liberation Army General Hospital, Beijing, China; ${ }^{4}$ Department of Cardiology, Chaoyang Integrated \\ Traditional Chinese and Western Medicine Emergency Rescue Center, Beijing, China; ${ }^{5}$ Geriatrics Department, Ward 2, The Seventh Medical \\ Center of Chinese People's Liberation Army General Hospital, Beijing, China \\ Contributions: (I) Conception and design: J Dong; (II) Administrative support: L Li; (III) Provision of study materials or patients: M Lu; (IV) \\ Collection and assembly of data: X Cheng; (V) Data analysis and interpretation: J Dong, Y Zhai; (VI) Manuscript writing: All authors; (VII) Final \\ approval of manuscript: All authors. \\ Correspondence to: Yucui Zhai. Geriatrics Department, Ward 2, The Seventh Medical Center of Chinese People's Liberation Army General Hospital, \\ Beijing, China. Email: zhaiyc084126@163.com.
}

Backgroundk Pressure ulcers (PU) refer to local tissue ulceration and necrosis caused by long-term compression and friction brought on by tissue ischemia and hypoxia. Diabetic wounds do not easily heal, and once a pressure ulceration occurs, it is difficult to deal with. The purpose of this study was to analyze the current research status of PUs in diabetic patients.

Methods: The Science Citation Index Expanded (SCI-E) database was searched with terms of "Pressure Ulcer" and "Diabetes". Citespace software was used to analyze the annual distribution of the number of target documents and the distribution of countries, institutions, journals, authors, and keywords used in these works.

Results: In all, 1271 documents were retrieved, with a total citation frequency of 47,081, and an h-index of 101 . The top 5 countries in terms of the number of publications were the United States, the United Kingdom, China, Australia, and the Netherlands; the top 5 countries in centrality were the Netherlands, the United States, Canada, Japan, and France. The institutions with the greatest number of publications were the University of Amsterdam, Cardiff University, The University of Washington, and the University of Manchester. The institutions with the highest centrality were the University of Amsterdam, the University of Groningen, the University of Washington, the University of Adelaide, Baylor College of Medicine, and Queensland University of Technology. The authors with a highest number of publications were Bus SA, Apelqvist J, and the International Working Group on the Diabetic Foot, and Hinchliffe RJ. Only 2 authors had a centrality score above 0.01. Journals such as Diabetes Metabolism Research and Reviews, Diabetes Care, and Fournal of Wound Care showed considerable influence in this field. Keyword analysis indicated that the use of keywords in this field is not uniform, and the focus of research on PUs in diabetic patients lies the risk and management of foot ulcers.

Conclusions: There are few studies concerning PUs in patients with diabetes and little collaboration between authors. The current focus in this field is on the risk and management of foot ulcers.

Keywords: Pressure ulcer (PU); diabetes; bibliometrics; risk; management

Submitted Jul 29, 2021. Accepted for publication Oct 19, 2021.

doi: 10.21037/apm-21-2757

View this article at: https://dx.doi.org/10.21037/apm-21-2757 


\section{Introduction}

Pressure ulcer (PU) refers to ulceration and necrosis of the local tissues of the body, especially the tissues of bone protuberances. In PU, the blood supply to the tissues is blocked due to long-term pressure and friction, resulting in skin and subcutaneous tissue ischemia and hypoxia (1). PU brings suffering to patients, reduces the quality of life of patients, prolongs the length of hospital stay, and increases medical expenses $(2,3)$. PUs often occur in patients who are bedridden for a long time $(4,5)$. As the proportion of older adults in the population continues to grow, the number of older adult patients with various chronic diseases, especially diabetes (4) and PUs has increased significantly. Diabetic wounds are not easily healed, and once a pressure sore occurs, management becomes extremely challenging (6). PUs in diabetic patients are mainly foot ulcers and arise because of peripheral neuropathy, which leads to long-term insensitivity to compression, necrosis, and the nonhealing of the compressed areas (7). Moreover, even if the necrotic site is amputated, the patient's risk of recurrent PU remains high $(8,9)$. Previous studies suggested that the main causes leading to the high risk of recurrent $\mathrm{PU}$ in patients with diabetes included advanced age, long-time pressure, malnutrition, uncontrolled blood sugar (10).

Regarding the problem of PU in patients with diabetes, research includes 4 major areas: mechanism, prevention, treatment, and prognosis (11). Bibliometrics is the analysis of the literature on a specific subject that can capture the current state of the research in a field. Bibliometrics is conducive to evaluating related research on a topic and provides researchers with a rough outline of the focus and existing problems in a field (12). Different from systematic review and meta-analysis which focused on some specific question (13), the purpose of this study was to analyze the current research state of PU research in patients with diabetes through a bibliometric approach.

\section{Methods}

\section{Data source}

At present, the main data source of bibliometrics is the Science Citation Index Expanded (SCI-E) database in the Web of Science Core Collection (WOSCC), which was founded and by the American Institute of Scientific Information in 1957 . The database contains papers from more than 8,000 important journals and their cited information. SCIE is not only an \valuable citation retrieval tool but is also an important platform for bibliometric and scientific research evaluation. Our study used SCIE as the target database for retrieval and analysis.

\section{Search strategy}

For topic retrieval, the topic terms were "Pressure Ulcer" and "Diabetes". The publication time of the target document was from the publication time of the earliest document that could be retrieved [1965] to the last retrieval date of this study (June 28, 2021).

\section{Analysis}

We exported all the records of the search results and the cited references into text format to create the original data file, and then used Citespace software to analyze the data file. The content of the analysis included the annual distribution of the number of target documents; the countries, institutions, and journals that published these articles; authors; keywords used in the articles; and changes in keywords frequency over time.

\section{Statistical analysis}

As the aim of this study was to capture and describe the current state of research in diabetic PU, no comparison between groups or correlation analysis was performed. The data are mainly expressed as numbers and percentages.

\section{Results}

\section{Search results}

The preliminary search results yielded a total of 1,356 research literature records, including 1,069 original articles, 185 reviews, 77 conference proceedings, 9 editorial materials, 5 early access papers, 5 meeting abstracts, 3 book chapters, 2 letters, and 1 note. After 85 duplicates were eliminated, 1,271 documents were entered into the final analysis (Table 1). In terms of annual change, the number of publications continued to increase for the most part (Table 2, Figure 1). The citation frequency of these documents totaled 47,081 citations, the h-index was 101 , and the average number of citations per document was 37.04 (Figure 2). The number of citations showed a significant increase year by year. 
Table 1 Analysis of document types in the search results (the absolute number in the table reflects the specific number of documents of each type; but there are duplicates, and the actual total is 1,271 )

\begin{tabular}{lcc}
\hline Literature type & Number & $\%(\mathrm{~N}=1,271)$ \\
\hline Articles & 1,069 & 84.11 \\
Review articles & 185 & 14.56 \\
Conference proceedings & 77 & 6.06 \\
Editorial materials & 9 & 0.71 \\
Early access & 5 & 0.39 \\
Meeting abstracts & 5 & 0.39 \\
Book chapters & 3 & 0.24 \\
Letters & 2 & 0.16 \\
Notes & 1 & 0.08 \\
\hline
\end{tabular}

\section{Countries and institutions}

In order to understand the distribution of countries from which the literature originated, we used CiteSpace software to analyze the text of search results and generate a map of countries (Figure 3) In all, 63 countries were recorded as the source of the published literature, and there were 314 instances of cooperation between countries. A similar map for institutions was also generated (Figure 4). In all, 161 institutions were identified, with 338 collaborations between institutions. The statistical results show that the top 5 countries in the number of publications consisted of the United States, the United Kingdom, China, Australia, and the Netherlands; the top 5 countries in centrality included the Netherlands, the United States, Canada, Japan, and France (Tables 3,4). The top institutions in terms of the number of published studies were the University of Amsterdam, Cardiff University, The University of Washington, and the University of Manchester. The institutions with the highest centrality included the University of Amsterdam, the University of Groningen, the University of Washington, the University of Adelaide, Baylor College of Medicine, and Queensland University of Technology (Tables 5,0).

\section{Author analysis}

The authors with a high number of publications included Bus SA, Apelqvist J, the International Working Group on the Diabetic Foot (IWGDF), and Hinchliffe RJ (Table 7).
Table 2 Annual change in the number of documents

\begin{tabular}{|c|c|c|}
\hline Publication year & Number & $\%(N=1,271)$ \\
\hline 2021 & 20 & 1.57 \\
\hline 2020 & 110 & 8.65 \\
\hline 2019 & 92 & 7.24 \\
\hline 2018 & 85 & 6.69 \\
\hline 2017 & 67 & 5.27 \\
\hline 2016 & 91 & 7.16 \\
\hline 2015 & 72 & 5.66 \\
\hline 2014 & 63 & 4.96 \\
\hline 2013 & 65 & 5.11 \\
\hline 2012 & 64 & 5.04 \\
\hline 2011 & 41 & 3.23 \\
\hline 2010 & 45 & 3.54 \\
\hline 2009 & 52 & 4.09 \\
\hline 2008 & 58 & 4.56 \\
\hline 2007 & 34 & 2.68 \\
\hline 2006 & 21 & 1.65 \\
\hline 2005 & 30 & 2.36 \\
\hline 2004 & 28 & 2.20 \\
\hline 2003 & 27 & 2.12 \\
\hline 2002 & 30 & 2.36 \\
\hline 2001 & 20 & 1.57 \\
\hline 2000 & 17 & 1.34 \\
\hline 1999 & 31 & 2.44 \\
\hline 1998 & 25 & 1.97 \\
\hline 1997 & 17 & 1.34 \\
\hline 1996 & 16 & 1.26 \\
\hline 1995 & 8 & 0.63 \\
\hline 1994 & 10 & 0.79 \\
\hline 1993 & 13 & 1.02 \\
\hline 1992 & 12 & 0.94 \\
\hline 1991 & 7 & 0.55 \\
\hline
\end{tabular}

Only 2 authors had a centrality score above 0.01 , and the IWGDF is a research group, which suggests that there is relatively little cooperation between authors (Table 8 , Figure 5). The most prolific authors also had a high 


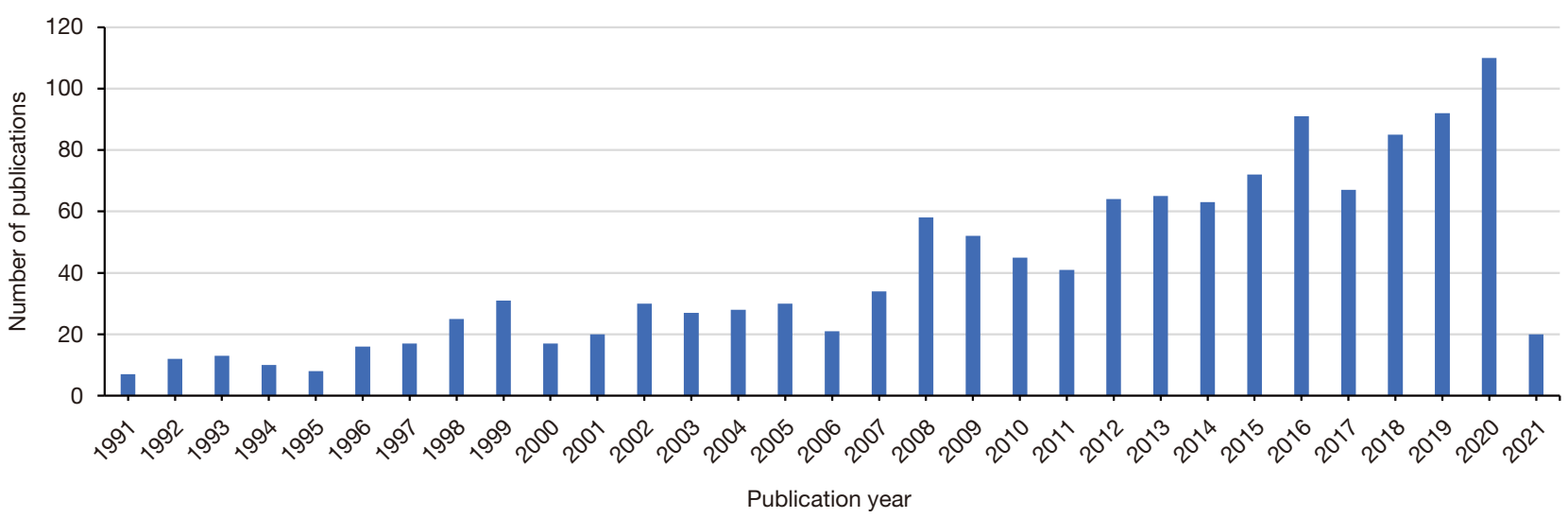

Figure 1 The annual trend of the number of publications.

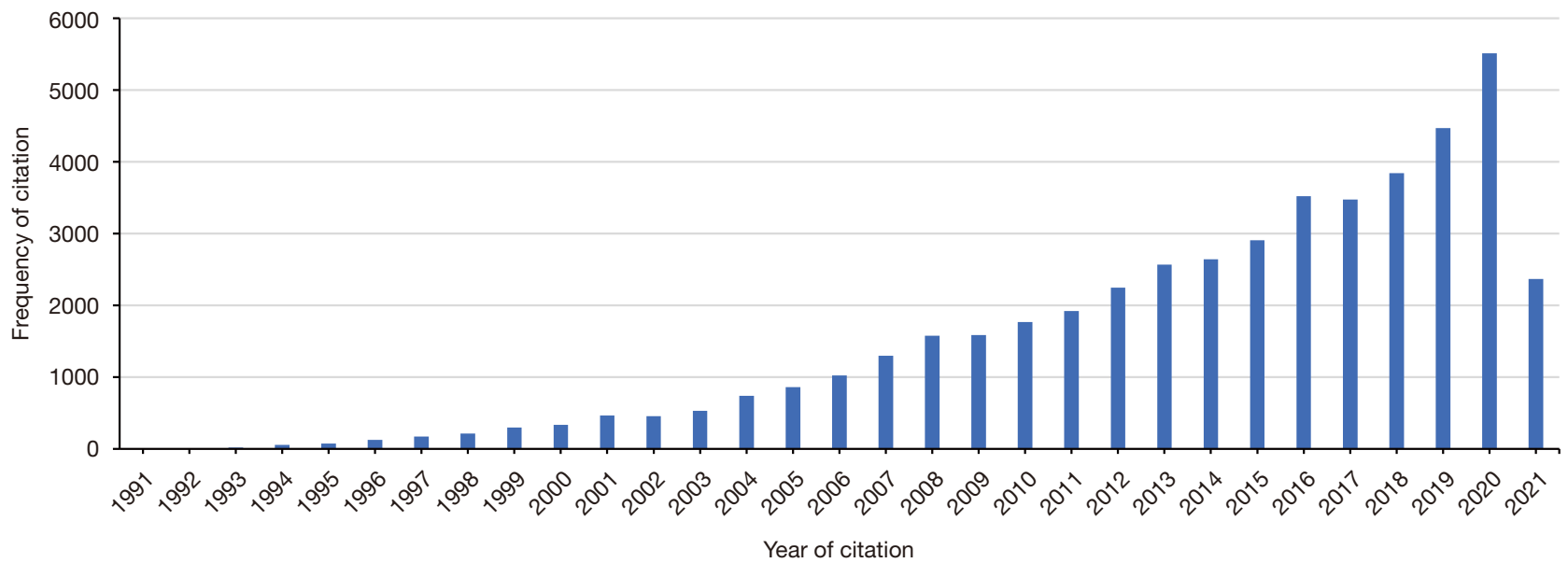

Figure 2 The annual trend of the number of citations.

frequency of citations. The top 5 most prolific authors were Armstrong DG, Boulton AJM, Bus SA, Lavery LA, and Singh N (Table 9); the top 5 most-cited authors were Reiber GE, Birke JA, Van Netten JJ, Wu SC, and Brownrigg JRW (Figure 6, Table 10).

\section{Distribution of journals}

The 1,271 articles in this study were from 469 journals. Among them, 11 journals published more than 20 articles (Table 11). These journals published 346 articles, accounting for $27.22 \%$ of the total literature (Table 11). Based on these results, it is speculated that journals such as Diabetes Metabolism Research and Reviews, Diabetes Care, and Fournal of Wound Care have considerable influence in this field compared with others. The top 5 journals by number of citations were Diabetes Care, Diabetes-metabolism research and reviews, Diabetic Medicine, International Wound fournal, and Diabetologia (Table 12). The top 5 journals for centrality were Cochrane Database Systematic Review, Arch Surg-Chicago, Med Clin N Am, BM7 Open, and Circ Res (Table 13).

\section{Keyword analysis}

We use CiteSpace software to analyze the use of keywords and generate a keyword co-occurrence map $(\mathrm{N}=248$, $\mathrm{E}=1,238)$. A total of 248 keywords were used in these documents and had 1,238 links between them. The top 5 most frequently used keywords were "diabetic foot ulcer", "diabetes", "risk", "ulcer", and "management" (Table 14). The top 4 keywords for centrality were "association", "guideline", "peripheral arterial disease", and "ankle" 


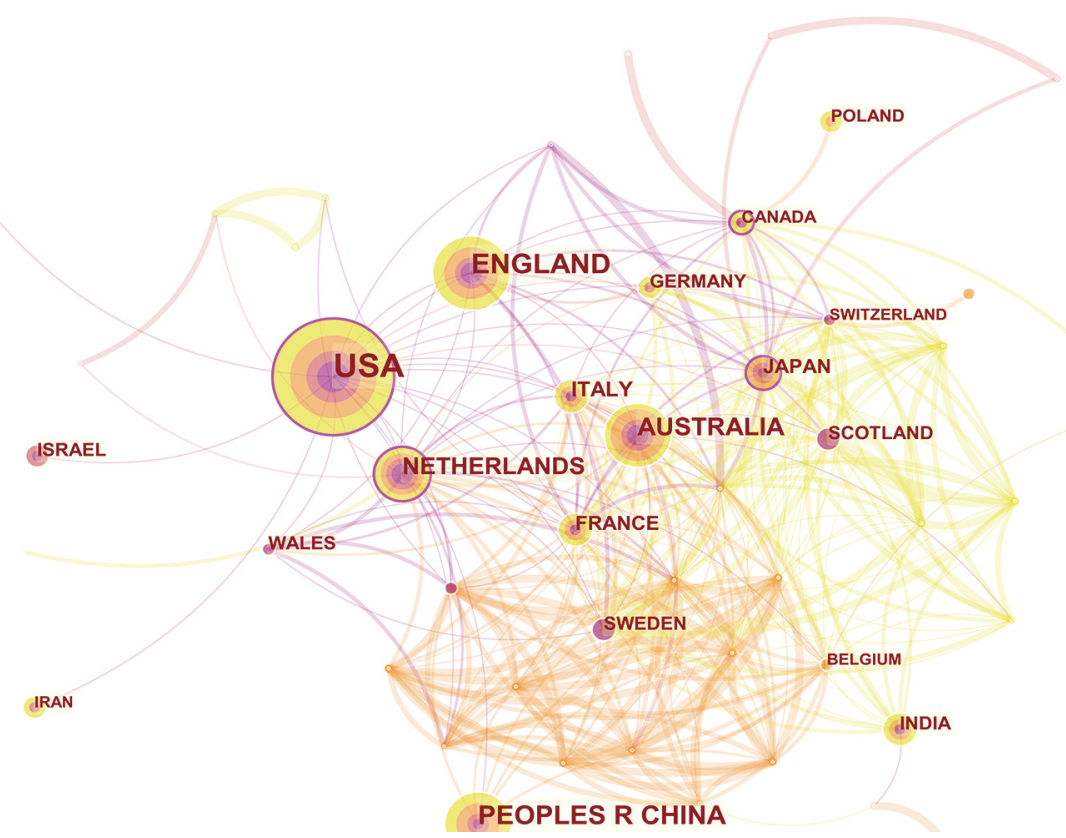

Figure 3 Visualization map of countries. N=63, E=314 ( $\mathrm{N}$ represents the number of network nodes, with 1 node representing 1 country or region; $\mathrm{E}$ represents the number of connections, with 1 connection representing a collaboration between 2 countries).

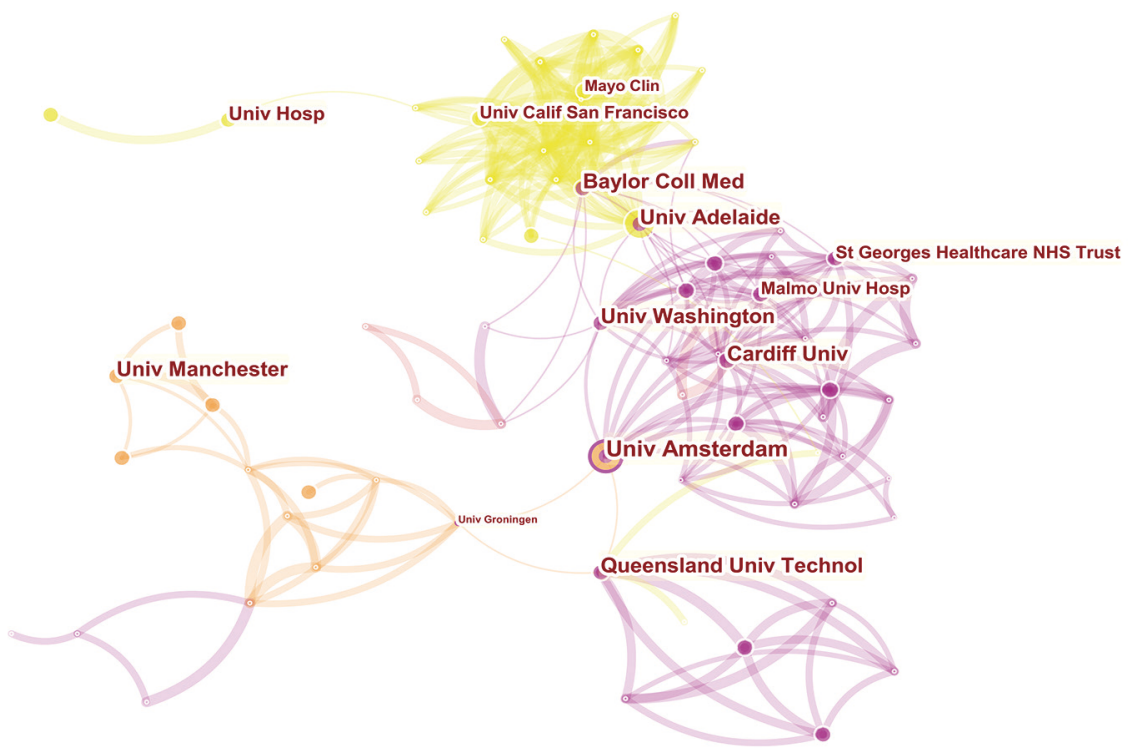

Figure 4 Visualized map of institutions. $\mathrm{N}=161, \mathrm{E}=338$ (N represents the number of network nodes, with 1 node representing 1 institution; E represents the number of connections, with 1 connection representing a collaboration between 2 institutions). 
Table 3 The top 10 countries in the number of publications

\begin{tabular}{lll}
\hline Rank & Country & Publications \\
\hline 1 & The United State of America & 109 \\
2 & England & 42 \\
3 & China & 36 \\
4 & Australia & 29 \\
5 & The Netherlands & 26 \\
6 & Italy & 17 \\
7 & Japan & 14 \\
8 & France & 13 \\
9 & Germany & 12 \\
10 & Scotland & 12 \\
\hline
\end{tabular}

Table 4 Top 10 countries in centrality

\begin{tabular}{lll}
\hline Rank & Countries & Centrality \\
\hline 1 & The Netherlands & 0.18 \\
2 & The United State of America & 0.16 \\
3 & Canada & 0.12 \\
4 & Japan & 0.11 \\
5 & France & 0.10 \\
6 & Switzerland & 0.06 \\
7 & Belgium & 0.05 \\
8 & Colombia & 0.05 \\
9 & Egypt & 0.05 \\
10 & Romania & 0.05
\end{tabular}

Table 5 Top 10 institutions in the number of publications

\begin{tabular}{lll}
\hline Rank & Institutions & Publications \\
\hline 1 & University of Amsterdam & 9 \\
2 & Cardiff University & 8 \\
3 & University of Washington & 8 \\
4 & University of Manchester & 8 \\
5 & University of Adelaide & 7 \\
6 & Baylor College of Medicine & 7 \\
7 & Queensland University of Technology & 7 \\
8 & Washington University Hospital & 6 \\
9 & University of Sao Paulo & 5 \\
10 & St Georges Healthcare NHS Trust & 5 \\
\hline
\end{tabular}

Table 6 Top 10 institutions in centrality

\begin{tabular}{lll}
\hline Rank & Institution & Centrality \\
\hline 1 & University of Amsterdam & 0.17 \\
2 & University of Groningen & 0.13 \\
3 & University of Washington & 0.08 \\
4 & University of Adelaide & 0.08 \\
5 & Baylor College of Medicine & 0.08 \\
6 & Queensland University of Technology & 0.08 \\
7 & University of Arizona & 0.06 \\
8 & Cardiff University & 0.05 \\
9 & Harvard Medical School & 0.05 \\
10 & Malmo University Hospital & 0.03 \\
\hline
\end{tabular}

Table 7 The top 10 authors by number of published works

\begin{tabular}{lll}
\hline Rank & Authors & Published works \\
\hline 1 & Bus SA & 10 \\
2 & Apelqvist J & 6 \\
3 & IWGDF & 6 \\
4 & Hinchliffe RJ & 5 \\
5 & Price PE & 4 \\
6 & Schaper NC & 4 \\
7 & Fitridge R & 3 \\
8 & Chuter VH & 3 \\
9 & Malecki MT & 3 \\
\hline IWGDF, The International Working Group for the Diabetic Foot.
\end{tabular}

Table 8 Top-ranked authors by centrality

\begin{tabular}{lcc}
\hline Rank & Authors & Centrality \\
\hline 1 & IWGDF & 0.03 \\
2 & Price PE & 0.01 \\
\hline
\end{tabular}

IWGDF, The International Working Group for the Diabetic Foot. 

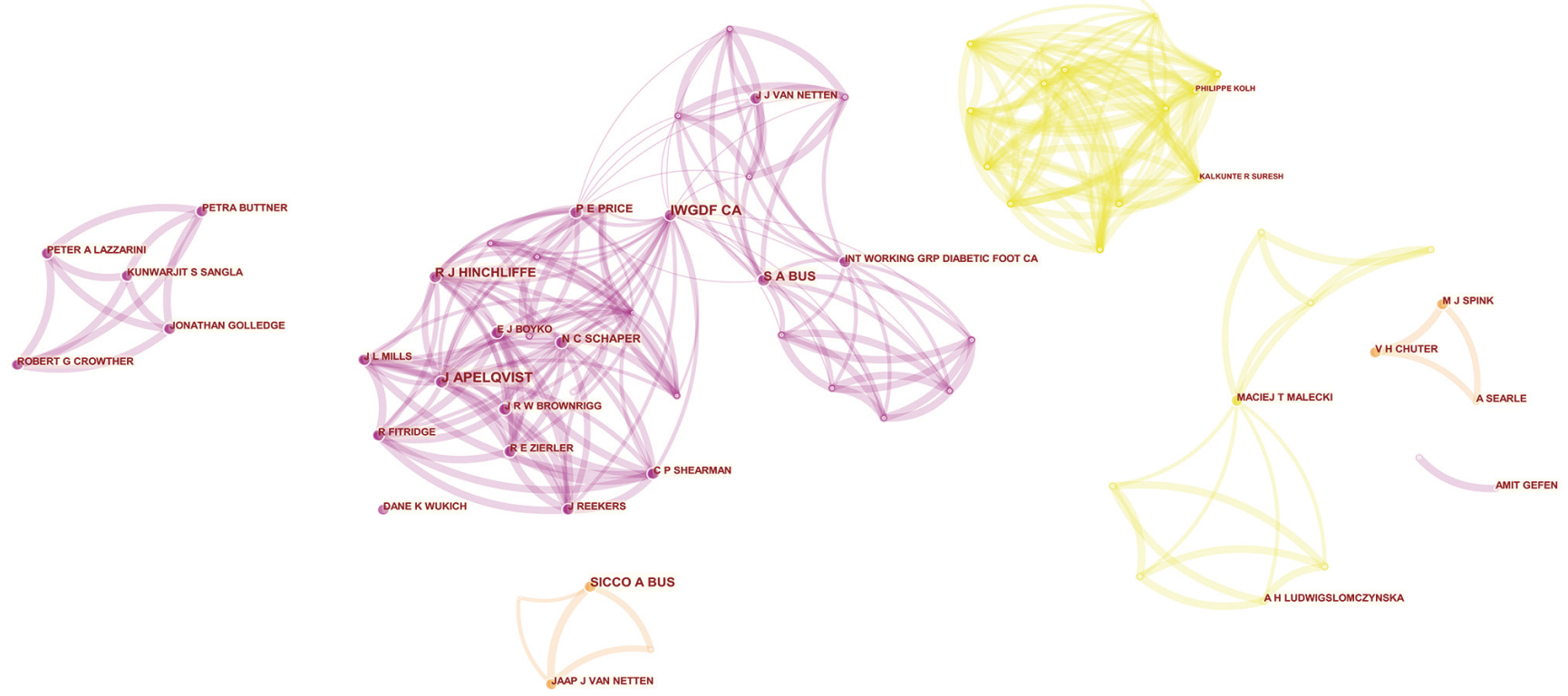

Figure 5 Visual map of the authors and coauthors.

Table 9 The top 10 most-cited authors by the number of times they were cited

\begin{tabular}{lll}
\hline Rank & Authors & Number of citations \\
\hline 1 & Armstrong DG & 95 \\
2 & Boulton AJM & 79 \\
3 & Bus SA & 72 \\
4 & Lavery LA & 67 \\
5 & Singh N & 50 \\
6 & PROMPERS L & 42 \\
7 & Cavanagh PR & 39 \\
8 & Frykberg RG & 37 \\
9 & Lipsky BA & 37 \\
10 & Veves A & 35 \\
\hline
\end{tabular}

(Table 15, Figure 7). Keyword analysis indicated that the use of keywords in this field is not uniform. According to the use of keywords, we speculate that the research on the subject of PUs in patients with diabetes is centralized around the risk and management of foot ulcers.

\section{Discussion}

In this study, 1,271 articles about PUs in diabetic patients were retrieved by topic term search. Relative to the large number of patients with diabetes and PUs, there were few studies in this field. Of the published works, we found that the United States, the United Kingdom, China and other countries had published more documents, while the Netherlands, the United States, Canada, and other countries engaged in more international cooperation. Among the institutions, the University of Amsterdam not only published the most documents but also collaborated the most. The number of articles published by each author was not high, and there was little collaboration between authors. In terms of journals, the literature was mainly published in professional journals of diabetes or wound management. Keywords were used frequently, and our analysis showed that the current research focuses lies on the management of the risk of PUs in patients with diabetes.

We found that although the United States, the United Kingdom, China, and other countries had published more documents, the country with the highest centrality was the Netherlands. Furthermore, the institution with the highest number of publications and centrality was the University of Amsterdam in the Netherlands, which may be attributed to the population size, high social welfare, and the status of the University of Amsterdam in the Netherlands. However, the analysis of the authors found that there was less collaboration between the authors. This result suggested that in most literature, the number of authors 


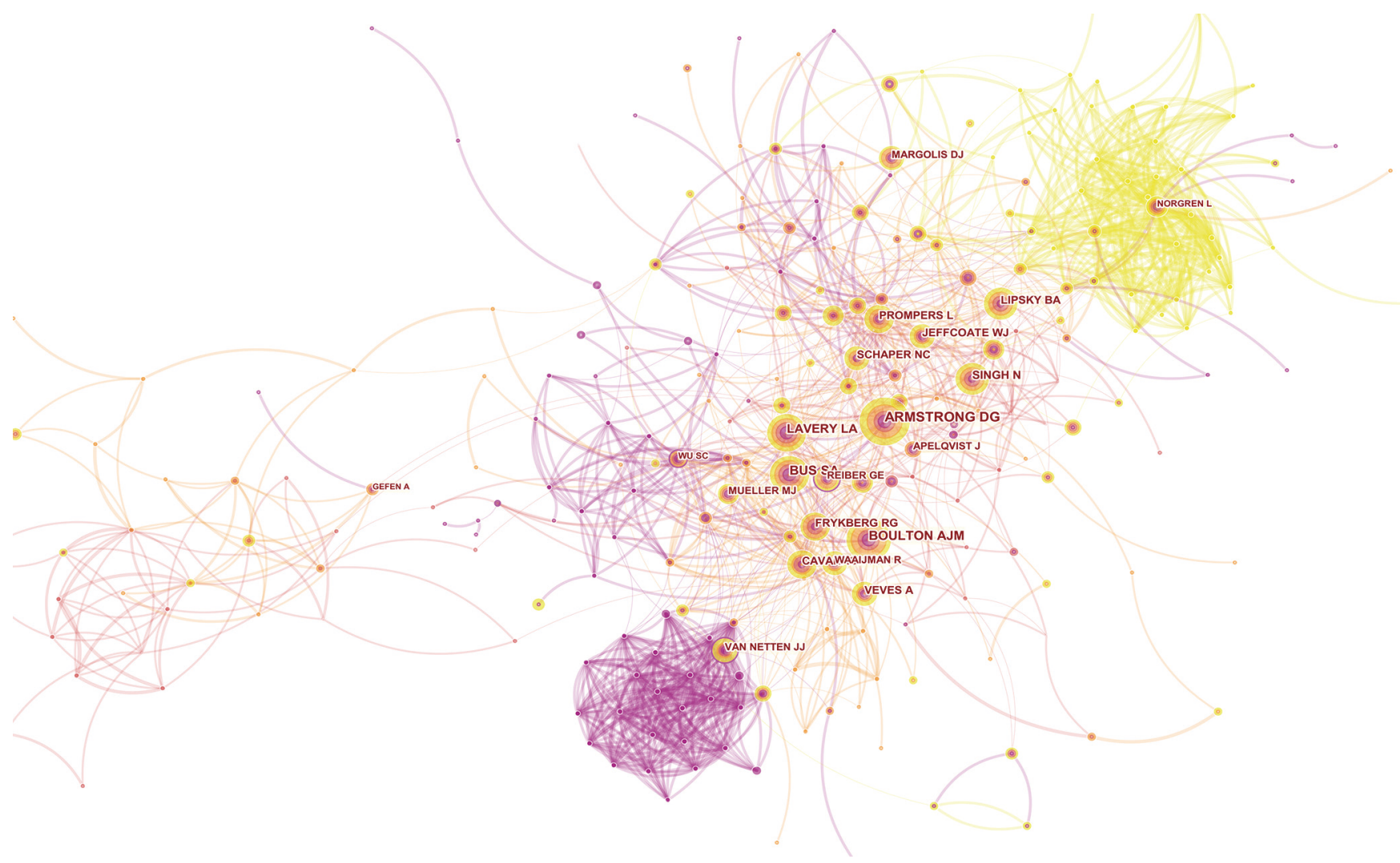

Figure 6 Visualized map of the authors and citations.

Table 10 Top 10 Centrally most-cited authors by centrality

\begin{tabular}{lll}
\hline Rank & Authors & Centrality \\
\hline 1 & Reiber GE & 0.11 \\
2 & Birke JA & 0.11 \\
3 & Van Netten JJ & 0.10 \\
4 & Wu SC & 0.10 \\
5 & Brownrigg JRW & 0.10 \\
6 & Cavanagh PR & 0.09 \\
7 & Sawacha Z & 0.09 \\
8 & Alavi A & 0.09 \\
9 & Frykberg RG & 0.08 \\
10 & Driver VR & 0.08 \\
\hline
\end{tabular}

was small and collaboration between different institution was also few. Additionally, we found there to be no pattern in the use of keywords. There are a total of 248 keywords used in the literature under this topic, many of which are repeated words. Based on the above results, we believe that there is still a lot of work to be done in the study of PUs in patients with diabetes. First, with the intensification of an aging society, the number of older adult patients and disabled older adults has gradually increased, resulting in a significant increase in the number of these patients who are bedridden or have limited mobility for extended periods. These patients often have diabetes and poor blood sugar control. They have a high risk of PUs, but this pressure is not restricted to the feet, and may occur especially in the sacrococcygeal area, hips, and joint protrusions. Related research should not be limited to the prevention and treatment of diabetic foot but should increase attention to PUs in other parts of the body. Second, according to our clinical practice and related literature reports, we know that once PUs occur in diabetic patients, especially older ones, it is very difficult to cure (14). Therefore, research should concentrate particularly on prevention. According to the current concepts in chronic disease management, prevention work should be integrated into the management of chronic diseases of diabetes, and the role of the chronic 
Table 11 Top 11 journals according to number of papers published

\begin{tabular}{lll}
\hline Publication titles & Number & \% $(\mathrm{N}=1,271)$ \\
\hline Diabetes Metabolism Research and Reviews & 54.25 & 46 \\
Diabetes Care & 38 & 2.62 \\
Journal of Wound Care & 37 & 2.99 \\
Diabetic Medicine & 29 & 2.28 \\
International Wound Journal & 29 & 2.28 \\
Wounds a Compendium of Clinical Research and Practice & 25 & 1.97 \\
Foot Ankle International & 24 & 1.89 \\
Journal of The American Podiatric Medical Association & 24 & 1.89 \\
Ostomy Wound Management & 20 & 1.57 \\
Diabetes Research and Clinical Practice & 20 & 1.57 \\
International Journal of Lower Extremity Wounds & & \\
\hline
\end{tabular}

Table 12 The top ranked journals according to number of citations

\begin{tabular}{lll}
\hline Rank & Journal & $\begin{array}{l}\text { Number of } \\
\text { citations }\end{array}$ \\
\hline 1 & Diabetes Care & 228 \\
2 & $\begin{array}{l}\text { Diabetes Metabolism Research and } \\
\text { Reviews }\end{array}$ & 148 \\
3 & Diabetic Medicine & 145 \\
4 & International Wound Journal & 118 \\
5 & Diabetologia & 115 \\
6 & Lancet & 113 \\
7 & Wound Repair Regeneration & 103 \\
8 & JAMA-Journal of American Medicine & 98 \\
9 & Association & 95 \\
10 & New England Journal of Medicine & 94 \\
\hline
\end{tabular}

disease management team should, as much as possible, focus on control of blood sugar, reducing the time of partial pressure on the patient's body, and improving the nutritional status of long-term bedridden patients.

Given the aging demographics of current society, PUs will become a greater problem throughout the world. Epidemiology shows that approximately 1-3 million patients acquire PU in the United States each year (15). The rate of PUs higher in hospitalized patients with acute and critical illness $(16,17)$; for instance, one study showed
Table 13 The top ranked journals by centrality

\begin{tabular}{lll}
\hline Rank & Journals & Centrality \\
\hline 1 & Cochrane DataBase of Systematic Review & 0.10 \\
2 & Archive of Surgery-Chicago & 0.09 \\
3 & Medical Clinics of North America & 0.08 \\
4 & BMJ Open & 0.07 \\
5 & Circulation Research & 0.07 \\
6 & Journal of Tissue Viability & 0.06 \\
7 & Science & 0.06 \\
8 & American Heart Journal & 0.06 \\
9 & Critical Care Medicine & 0.06 \\
10 & Advances in Wound Care & 0.05 \\
\hline
\end{tabular}

that of 42,000 patients, $14.8 \%$ had PUs (18). Therefore, for older adult patients, especially those with diabetes or critical illness, special attention should be paid to the prevention and treatment of PUs.

There have been no breakthroughs in the treatment of PUs. Although PUs are small, the mechanisms involved are complicated. Moreover, if the pressure on the diseased area cannot be continuously relieved, it will be difficult for any treatment to exert a real effect (19). The mechanism of PUs involves the following: first, for a variety of reasons, the local soft tissues of the bone protrusion may be continuously compressed for a long time, which directly leads blockage in local blood supply, requiring the pressure 
Table 14 Top 10 most frequently used keywords

\begin{tabular}{lll}
\hline Rank & Keywords & Number of utility \\
\hline 1 & Diabetic foot ulcer & 121 \\
2 & Diabetes & 90 \\
3 & Risk & 76 \\
4 & Ulcer & 68 \\
5 & Management & 59 \\
6 & Pressure ulcer & 46 \\
7 & Prevention & 44 \\
8 & Pressure & 36 \\
9 & Amputation & 35 \\
10 & Plantar pressure & 34 \\
\hline
\end{tabular}

Table 15 Top 10 keywords by centrality

\begin{tabular}{lll}
\hline Rank & Keywords & Centrality \\
\hline 1 & Association & 0.17 \\
2 & Guideline & 0.11 \\
3 & Peripheral arterial disease & 0.08 \\
4 & Ankle & 0.08 \\
5 & IWGDF guidance & 0.07 \\
6 & Quality of life & 0.07 \\
7 & Diabetes & 0.06 \\
8 & Ulcer & 0.06 \\
9 & Prevention & 0.06 \\
10 & Infection & 0.06 \\
\hline
\end{tabular}

IWGDF, The International Working Group for the Diabetic Foot.

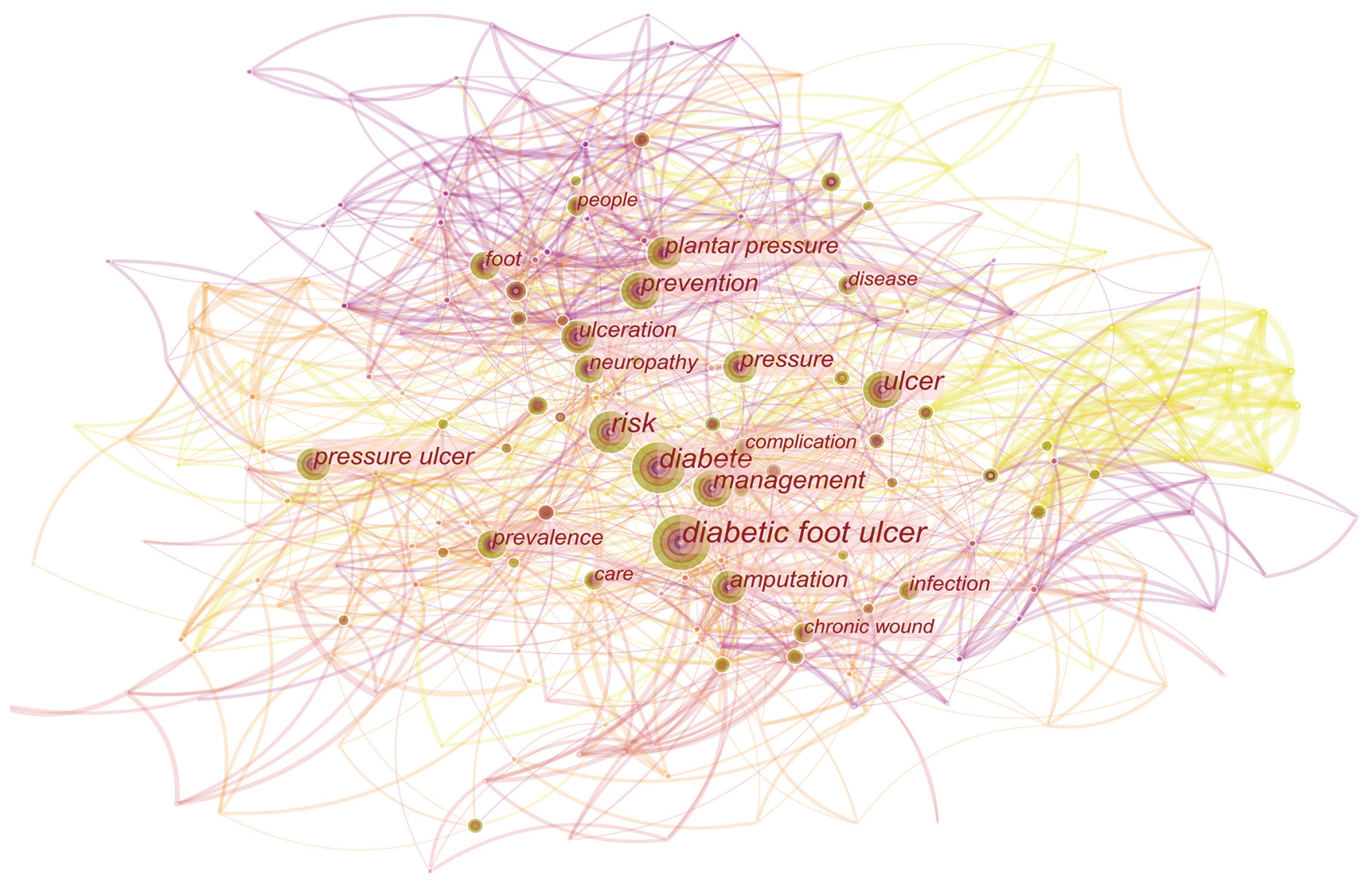

Figure 7 Keyword co-occurrence diagram. 
to be effectively relieved. Second, shear and friction can damage the subcutaneous vascular bed and cause ischemia (20). In addition, the moist skin in the local environment remains in maceration for an extended period, which makes the skin more susceptible to shear and friction damage, and creates an environment conducive to the breeding of pathogens and local infection (21). Current treatment of PUs mainly includes medicinal dressings and external disinfectants containing silver and iodine (22). Relevant drug treatment studies are marred by inconsistent drug formulation specifications, lack of evaluations with an endpoint of complete PU healing, and a lack of large-scale, multicenter, randomized controlled studies. Moreover, few analyses on systemic adverse drug reactions exist (23). We believe that the medical treatment of PUs should focus on promoting local tissue healing, increasing local drug concentration, prolonging drug release time, and reducing systemic adverse drug reactions. The medication method should focus on topical administration, and a drugcarrying matrix with good performance to reduce the impact of sweat and secretions on drug adhesion should be developed (24).

In the prevention of PUs in patients with diabetes, the most important issue is controlling blood sugar. It should be noted that, according to the current diabetes prevention and control guidelines, the goals of blood sugar control for older adults and susceptible patients should be appropriately relaxed (25). Excessively strict dietary control that leads to malnutrition of patients should be avoided, as this makes patients prone to PUs and is not conducive to their being healed (26). Additionally, diabetic patients who have been bedridden for an extended period should pay full attention to reducing the long-term pressure on the body. During the nursing process, attention should be paid to observing the local skin and reducing the influence of shear and friction in the operation $(22,27)$. In conclusion, our present study revealed an overview of the status of PU research in diabetic patient. Taking our findings into consideration, investigators should put more attention to this field to promote the care for these diabetic patients with PU. Maybe in the future, the treatment and prevention methods for these patients will be made great progress.

Some limitations of this study should be noted. First, as this study used topic term retrieval, we might have missed documents that could be retrieved by other retrieval strategies, resulting in a nonrepresentative analysis of the state of research. This can also be confirmed by the use of keywords, because we found that the use of keywords was rather confusing and led us to omit some when conducting our search. Second, there might have been a few documents derived from the same research, leading to the possibility of duplicates being present in the analysis.

\section{Acknowledgments}

Funding: None.

\section{Footnote}

Conflicts of Interest: All authors have completed the ICMJE uniform disclosure form (available at https://dx.doi. org/10.21037/apm-21-2757). The authors have no conflicts of interest to declare.

Ethical Statement: The authors are accountable for all aspects of the work in ensuring that questions related to the accuracy or integrity of any part of the work are appropriately investigated and resolved.

Open Access Statement: This is an Open Access article distributed in accordance with the Creative Commons Attribution-NonCommercial-NoDerivs 4.0 International License (CC BY-NC-ND 4.0), which permits the noncommercial replication and distribution of the article with the strict proviso that no changes or edits are made and the original work is properly cited (including links to both the formal publication through the relevant DOI and the license). See: https://creativecommons.org/licenses/by-nc-nd/4.0/.

\section{References}

1. Hajhosseini B, Longaker MT, Gurtner GC. Pressure Injury. Ann Surg 2020;271:671-9.

2. Sen CK. Human Wound and Its Burden: Updated 2020 Compendium of Estimates. Adv Wound Care (New Rochelle) 2021;10:281-92.

3. López-Franco MD, Parra-Anguita L, Comino-Sanz IM, et al. Attitudes of Spanish Nurses towards Pressure Injury Prevention and Psychometric Characteristics of the Spanish Version of the APuP Instrument. Int $\mathrm{J}$ Environ Res Public Health 2020;17:8543.

4. Børsting TE, Tvedt CR, Skogestad IJ, et al. Prevalence of pressure ulcer and associated risk factors in middleand older-aged medical inpatients in Norway. J Clin Nurs 2018;27:e535-43.

5. Fritz A, Gericke L, Höch A, et al. Time-to-treatment is a 
risk factor for the development of pressure ulcers in elderly patients with fractures of the pelvis and acetabulum. Injury 2020;51:352-6.

6. Rayman G, Vas P, Dhatariya K, et al. Guidelines on use of interventions to enhance healing of chronic foot ulcers in diabetes (IWGDF 2019 update). Diabetes Metab Res Rev 2020;36 Suppl 1:e3283.

7. van Netten JJ, Raspovic A, Lavery LA, et al. Prevention of foot ulcers in the at-risk patient with diabetes: a systematic review. Diabetes Metab Res Rev 2020;36 Suppl 1:e3270.

8. Blume P, Wu S. Updating the Diabetic Foot Treatment Algorithm: Recommendations on Treatment Using Advanced Medicine and Therapies. Wounds 2018;30:29-35.

9. Brownrigg JR, Hinchliffe RJ, Apelqvist J, et al. Performance of prognostic markers in the prediction of wound healing or amputation among patients with foot ulcers in diabetes: a systematic review. Diabetes Metab Res Rev 2016;32 Suppl 1:128-35.

10. Wei R, Chen HL, Zha ML, et al. Diabetes and pressure ulcer risk in hip fracture patients: a meta-analysis. J Wound Care 2017; 26:519-527.

11. Primadhi RA, Herman H. Diabetic foot: Which one comes first, the ulcer or the contracture? World J Orthop 2021;12:61-8.

12. Roldan-Valadez E, Salazar-Ruiz SY, Ibarra-Contreras R, et al. Current concepts on bibliometrics: a brief review about impact factor, Eigenfactor score, CiteScore, SCImago Journal Rank, Source-Normalised Impact per Paper, H-index, and alternative metrics. Ir J Med Sci 2019;188:939-51.

13. Liu P, He W, Chen HL. Diabetes mellitus as a risk factor for surgery-related pressure ulcers: a meta-analysis. J Wound Ostomy Continence Nurs 2012;39:495-9.

14. Jaul E. Assessment and management of pressure ulcers in the elderly: current strategies. Drugs Aging 2010;27:311-25.

15. Attali E, Yogev Y. The impact of advanced maternal age on pregnancy outcome. Best Pract Res Clin Obstet Gynaecol 2021;70:2-9.

Cite this article as: Dong J, Li L, Lu M, Cheng X, Zhai Y. Pressure ulcers in patients with diabetes: a bibliometrics analysis. Ann Palliat Med 2021;10(10):10515-10526. doi: 10.21037/apm-21-2757
16. Robnett MK. The incidence of skin breakdown in a surgical intensive care unit. J Nurs Qual Assur 1986;1:77-81.

17. Pachá HHP, Faria JIL, Oliveira KA, et al. Pressure Ulcer in Intensive Care Units: a case-control study. Rev Bras Enferm 2018;71:3027-34.

18. Amlung SR, Miller WL, Bosley LM. The 1999 National Pressure Ulcer Prevalence Survey: a benchmarking approach. Adv Skin Wound Care 2001;14:297-301.

19. Teo CSM, Claire CA, Lopez V, et al. Pressure injury prevention and management practices among nurses: A realist case study. Int Wound J 2019;16:153-63.

20. Bhattacharya S, Mishra RK. Pressure ulcers: Current understanding and newer modalities of treatment. Indian J Plast Surg 2015;48:4-16.

21. Edsberg LE. Pressure ulcer tissue histology: an appraisal of current knowledge. Ostomy Wound Manage 2007;53:40-9.

22. Mervis JS, Phillips TJ. Pressure ulcers: Prevention and management. J Am Acad Dermatol 2019;81:893-902.

23. Chou R, Dana T, Bougatsos C, et al. Pressure ulcer risk assessment and prevention: a systematic comparative effectiveness review. Ann Intern Med 2013;159:28-38.

24. Gould L, Stuntz M, Giovannelli M, et al. Wound Healing Society 2015 update on guidelines for pressure ulcers. Wound Repair Regen 2016;24:145-62.

25. LeRoith D, Biessels GJ, Braithwaite SS, et al. Treatment of Diabetes in Older Adults: An Endocrine Society* Clinical Practice Guideline. J Clin Endocrinol Metab 2019;104:1520-74.

26. Munoz N, Posthauer ME, Cereda E, et al. The Role of Nutrition for Pressure Injury Prevention and Healing: The 2019 International Clinical Practice Guideline Recommendations. Adv Skin Wound Care 2020;33:123-36.

27. Fremmelevholm A, Soegaard K. Pressure ulcer prevention in hospitals: a successful nurse-led clinical quality improvement intervention. Br J Nurs 2019;28:S6-S11.

(English Language Editor: J. Gray) 